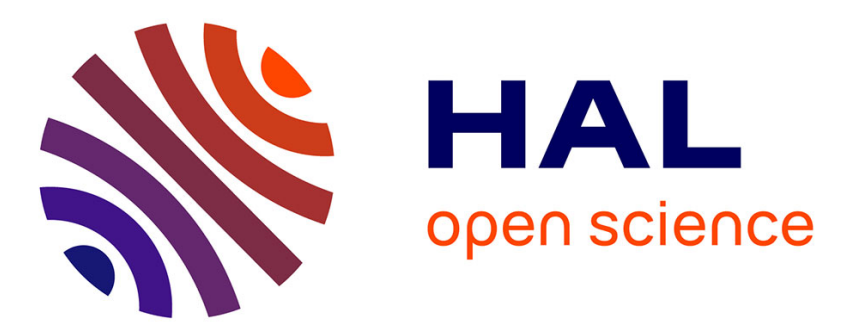

\title{
Rheological properties of mixed gels made of microparticulated whey proteins and beta-lactoglobulin
}

Denis Renard, P. Robert, S. Faucheron, Christian Sanchez

\section{To cite this version:}

Denis Renard, P. Robert, S. Faucheron, Christian Sanchez. Rheological properties of mixed gels made of microparticulated whey proteins and beta-lactoglobulin. Colloids and Surfaces B: Biointerfaces, 1999, 12, pp.113-121. 10.1016/S0927-7765(98)00068-X . hal-02687352

\section{HAL Id: hal-02687352 \\ https://hal.inrae.fr/hal-02687352}

Submitted on 1 Jun 2020

HAL is a multi-disciplinary open access archive for the deposit and dissemination of scientific research documents, whether they are published or not. The documents may come from teaching and research institutions in France or abroad, or from public or private research centers.
L'archive ouverte pluridisciplinaire HAL, est destinée au dépôt et à la diffusion de documents scientifiques de niveau recherche, publiés ou non, émanant des établissements d'enseignement et de recherche français ou étrangers, des laboratoires publics ou privés. 


\title{
Rheological properties of mixed gels made of microparticulated whey proteins and $\beta$-lactoglobulin
}

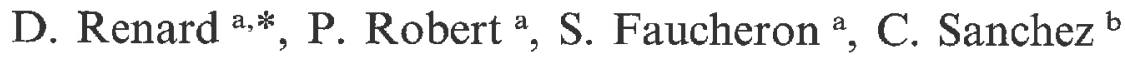 \\ ${ }^{a}$ Laboratoire de Physico-Chimie des Macromolécules, INRA-BP 71627-44316, Nantes Cedex 03, France \\ ' Laboratoire de Physico-Chimie et Génie Alimentaires, ENSAIA INPL-54500, Vandoeuvre-lès-Nancy, France
}

\begin{abstract}
Microparticulated whey proteins (MWP) in suspension or included in a globular protein network revealed that the degree of flocculation was important in the final structure of the material. The MWP dispersions developed an antithixotropic character when low shear rate was applied to the system even at low temperature. Similar results were obtained on globular protein solutions and could be interpreted in terms of an orthokinetic aggregation. MWP participated to the formation and reinforcement of heat-induced $\beta$-lactoglobulin (BLG) gels. The mechanical properties of mixed gels demonstrated synergestic effects at low MWP massic fraction (BLG:MWP ratio higher than 2:1). A possible interpretation would be that both interaction of MWP with the network and flocculation of the MWP inside the pores could occur. However, increasing the fraction of MWP induced heterogeneities in the protein network. In particular, micro-phase separation due to steric hindrance effects or thermodynamic incompatibility between the two components could occur and decrease viscoelastic properties of mixed gels. (C) 1999 Elsevier Science B.V. All rights reserved.
\end{abstract}

Keywords: $\beta$-lactoglobulin; Microparticulated whey proteins; Antithixotropy; Aggregation; Mixed gels

\section{Introduction}

Microparticles issued from food proteins can be regarded as both soluble and insoluble aggregates of controlled size. They are usually obtained by thermal aggregation under strong shear conditions or by coacervation of globular proteins. Microparticles generally present better functional properties than the native proteins used to pro-

* Corresponding author. Fax: +33-2-40675043; e-mail: renardde@nantes.inra.fr. duce them [1]. They are used as fat replacers, texturing or stabilizing agents for ready-to-eat food dispersions or emulsions, and as microcapsules for cosmetic, pharmaceutical or medical purposes $[1,2]$.

An optimised use of these new materials supposes a better knowledge of their functional properties and in particular, of their thermal stability. In fact, the effect of microparticles on thermal gelation of globular proteins remains to be studied. Scientific basis are needed to understand the heat treatment of foods containing microparticles 
and consequently the extensive aggregation of particles and appearance of grittiness. The problem seems very complex as microparticulated proteins correspond to a heterogeneous population of native soluble species and colloidal species (soluble and insoluble aggregates) defined on a centrifugation criterium [3].

Previous results obtained on diluted whey protein solutions showed that the presence of more than $3.5 \%$ microparticles accelerated the thermal aggregation and shifted the mechanism from homogeneous to biphasic [3]. Interactions between whey proteins and microparticles were thought to be at the origin of the shift.

In the present paper, a rheological study was achieved on microparticulated whey protein (MWP) dispersions in order to determine the structure and stability of such colloidal systems. Microparticle concentration, temperature and ageing of the dispersions were more particularly taken into account. Moreover, the behaviour of the new mixed gels obtained by mixing MWP with $\beta$-lactoglobulin (BLG) was compared to that of single BLG gels in terms of rate of cross-linking and final gel structure. The potential of MWP to be associated with the gel protein matrix was evaluated.

\section{Experimental}

\subsection{Samples}

Bovine BLG was purchased from ICN Biomedicals (lot $\mathrm{n}^{\circ}$ 76097) and MWP powder (Simplesse $^{\circledR} 100$, lot $\mathrm{n}^{\circ} 40114 \mathrm{~F}$ ) was a gift from NutraSweet Kelco (Monsanto SNC, Division NutraSweet Kelco). MWP were dispersed at $4^{\circ} \mathrm{C}$ in $0.1 \mathrm{M} \mathrm{NaCl}$ under gentle stirring for 4 h. The $\mathrm{pH}$ of the dispersions was adjusted to $7.0 \pm 0.02$ with $0.1 \mathrm{~N} \mathrm{NaOH}$. The same procedure was applied to prepare BLG solutions. The initial $\mathrm{pH}$ and concentration values of MWP dispersion were 6.3 and $25 \%(\mathrm{w} / \mathrm{w})$, respectively. For BLG solution, the initial $\mathrm{pH}$ and concentration values were 6.1 and $10 \%(w / w)$, respectively.

\subsection{Size distributions}

The relative size and volume distributions of MWP were determined using a Malvern Mastersizer MS20 (Malvern Instruments, Malvern, UK). A $2 \mathrm{~mW}$ He-Ne laser beam $(\lambda=633 \mathrm{~nm})$ and a $45 \mathrm{~mm}$ focus lens were used.

\subsection{Compositional analyses}

The protein content of MWP was determined according to the macro-Kjeldahl method ( $\mathrm{N} \times$ 6.38). The non protein nitrogen (NPN) fraction was based on TCA $12 \%(\mathrm{v} / \mathrm{v})$ precipitation before determination of nitrogen content. The lactose content was measured by High Performance Anion Exchange Chromatography equipped with a Pulsed Amperometric Detector (HPAEC-PAD) with a Carbopac PA1 column. The solvent used was $\mathrm{NaOH} 0.1 \mathrm{M}$ and the column was previously calibrated with standard sugars. The salt content $\left(\mathrm{Ca}^{2+}, \mathrm{Na}^{+}\right.$and $\left.\mathrm{K}^{+}\right)$was determined by atomic absorption.

\subsection{Solubility of the different protein fractions}

The nitrogen solubility index (NSI) of MWP and $\mathrm{BLG}$ was determined at $\mathrm{pH} 4.6$ from the ratio of the nitrogen content $\left(N_{s}\right)$ of the supernatant relative to the nitrogen content of the dispersion before centrifugation $\left(N_{0}\right)$. The protein solubility of MWP was also determined at $\mathrm{pH} 6.0$ as described in [3]. The comparison of protein solubility at $\mathrm{pH} 4.6$ and 6.0 provides a mean to assess the extent of protein heat-denaturation/aggregation during processing of MWP [4]. Under the experimental conditions, three protein fractions were defined: (1) a fraction containing the native soluble proteins (NSP); (2) a fraction containing the soluble aggregated proteins (SAP) and (3) a fraction with the insoluble aggregated proteins (IAP). Further analysis was performed to identify the NSP through Reversed Phase-High Performance Liquid Chromatography (RPHPLC) using a Macherey-Nagel column $(250 \times 4$ $\mathrm{mm}$ ) as described by Pearce [5]. The elution was done at a flow rate of $1 \mathrm{ml} \mathrm{min}^{-1}$ and $T=30^{\circ} \mathrm{C}$ 
Table 1

Chemical composition (\% w/w) of microparticulated whey proteins (MWP) and $\beta$-lactoglobulin (BLG)

\begin{tabular}{|c|c|c|c|c|c|c|c|c|c|c|c|}
\hline \multirow[t]{2}{*}{ Protein source } & \multirow[t]{2}{*}{ Protein } & \multirow[t]{2}{*}{ Moisture } & \multirow[t]{2}{*}{ Fat } & \multirow[t]{2}{*}{ Lactose } & \multirow[t]{2}{*}{$\mathrm{Ca}^{2+}$} & \multirow[t]{2}{*}{$\mathrm{Na}^{+}$} & \multirow[t]{2}{*}{$\mathrm{K}^{+}$} & \multirow[t]{2}{*}{ NPN } & \multicolumn{3}{|c|}{ Protein fractions } \\
\hline & & & & & & & & & NSP & SAP & IAP \\
\hline MWP (Simplesse ${ }^{\circledR} 100$ ) & 48.1 & 3.9 & $4.2^{\mathrm{a}}$ & 34.1 & 0.7 & 0.54 & 1.0 & 2.06 & 25.4 & 32.5 & 42.1 \\
\hline BLG & 92 & 3.8 & $\mathrm{Nd}$ & Nd & 0.8 & 0.7 & 1.4 & Nd & $\mathrm{Nd}$ & $\mathrm{Nd}$ & $\mathrm{Nd}$ \\
\hline
\end{tabular}

a Given by the manufacturer.

Nd, not determined; MWP, microparticulated whey proteins; BLG, $\beta$-lactoglobulin, NPN, non protein nitrogen; NSP, native soluble proteins; SAP, soluble aggregated proteins; IAP, insoluble aggregated proteins.

and the protein detection was carried out by UV absorption at $280 \mathrm{~nm}$.

The effective BLG concentrations of mixed soIutions were calculated according to the NSP fraction included in MWP sample.

\subsection{Rheological measurements}

MWP dispersions were studied through equilibrium viscosity, dynamic shear and relaxation measurements at $25^{\circ} \mathrm{C}$ using a Couette-type viscometer (Low-shear 40, Contraves, Switzerland). The measurements for three independent dispersion preparations were duplicated.

Small-amplitude oscillatory shear experiments were performed at $80^{\circ} \mathrm{C}$ and after quenching at $25^{\circ} \mathrm{C}$ on both BLG and BLG:MWP gels with a Carri-Med CS100 rheometer using the cone-plate geometry (diameter $2 \mathrm{~cm}$, angle $\left.4^{\circ}\right)$. Gels $(2 \mathrm{~h}$ at $80^{\circ} \mathrm{C}$ ) were formed in-situ in the rheometer and both storage and loss moduli were recorded at a fixed frequency of $1 \mathrm{~Hz}$ and a minimal strain amplitude of 0.01 (the rheometer allows the measurements of torque values for a minimum strain value of 0.01 ). After quenching at $25^{\circ} \mathrm{C}$ and $1 \mathrm{~h}$ rest (we previously checked that storage and loss moduli at a fixed frequency kept constant after quenching), the mechanical spectra were recorded between $10^{-3}$ and $10 \mathrm{~Hz}$ under 0.03 strain amplitude. The measurements were done in triplicate. We checked that stress-strain linearity limit was up to 0.18 for BLG gel alone $(4 \% \mathrm{w} / \mathrm{w})$ and decreased up to 0.07 for BLG:MWP mixed gels (1:3.3 ratio).

\section{Results}

\subsection{Protein characterization and analysis}

The compositions of the MWP and BLG samples were given in Tables 1 and 2. MWP contained essentially proteins $(48.1 \%)$ and lactose (34.1\%). The NSIs were 58 and $97.6 \%$ for MWP and BLG samples, respectively. The detailed analysis of the protein fraction in the MWP starting material gave $25.4 \%$ native soluble proteins (NSP), 32.5\% soluble aggregated proteins (SAP) and $42.1 \%$ insoluble aggregated proteins (IAP) (Table 1). An analysis of the NSP fraction by RP-HPLC gave evidence of the presence of the two variants $A$ and $B$ of $B L G, \alpha$-lactalbumin and bovine serum albumin in roughly equal amounts (Table 2).

The size distributions on both number and volume basis of MWP dispersions gave a restricted number of microparticles with diameters

Table 2

Chemical composition $(\% \mathrm{w} / \mathrm{w})$ of native soluble proteins (NSP) fraction in microparticulated whey proteins (MWP) dispersions

\begin{tabular}{lr}
\hline NSP & $\% \mathrm{w} / \mathrm{w}$ \\
\hline Bovine serum albumin & 3.05 \\
$\alpha$-lactalbumin & 3.56 \\
$\beta$-lactoglobulin B & 2.56 \\
$\beta$-lactoglobulin A & 3.03 \\
& $12.2^{\mathrm{a}}$ \\
\hline
\end{tabular}

a Corresponding to $25.4 \%$ of total protein content. NSP, native soluble proteins. 


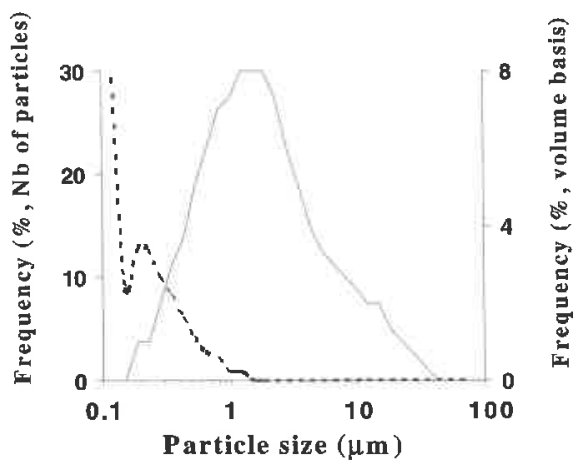

Fig. 1. Typical size distributions of microparticulated whey protein (MWP) dispersion at $2 \%(\mathrm{w} / \mathrm{w}) \mathrm{pH} 7$ in $0.1 \mathrm{M} \mathrm{NaCl}$, $T=20^{\circ} \mathrm{C}$. Frequency given on a volume basis (-) and on a number of particles basis (-----).

ranging from 10 to $40 \mu \mathrm{m}$ (Fig. 1). The MWP diameter distribution was in the 0.1-2 $\mu \mathrm{m}$ range with an average diameter $D_{v 0.5}$ of $1.47 \mu \mathrm{m}$. The starting material was thus in accordance with a restricted sedimentation process at room temperature.

\subsection{Rheological properties of microparticulated whey protein dispersions}

Fig. 2 showed viscosity $\eta$ (Pa.s) as a function of time at different shear rates for MWP dispersions $(20 \% \mathrm{w} / \mathrm{w})$ obtained at $\mathrm{pH} 7$ and $\mathrm{NaCl} 0.1 \mathrm{M}$.

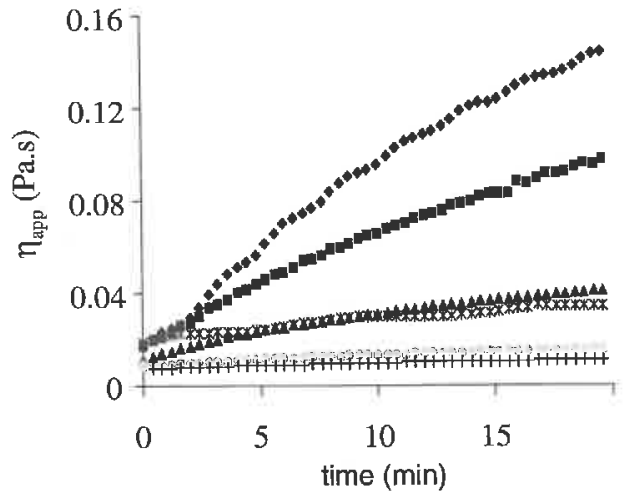

Fig. 2. Evolution of the apparent viscosity $\eta_{\text {app }}$ (Pa.s) at $T=20^{\circ} \mathrm{C}$ of microparticulated whey protein (MWP) dispersions $20 \%(\mathrm{w} / \mathrm{w}) \mathrm{pH} 70.1 \mathrm{M} \mathrm{NaCl}$ as a function of time for

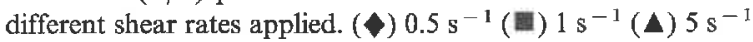
(*) $10 \mathrm{~s}^{-1}(\bullet) 50 \mathrm{~s}^{-1}(+) 100 \mathrm{~s}^{-1}$.

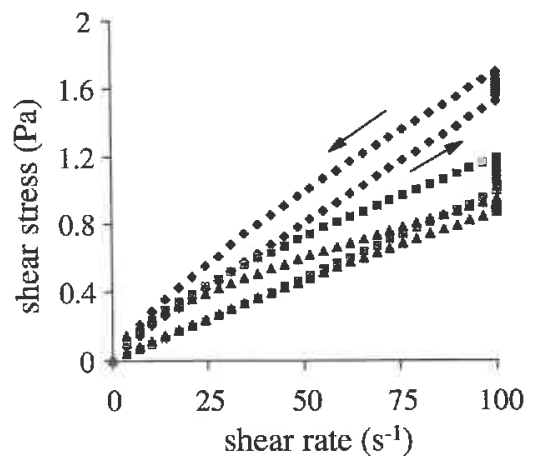

Fig. 3. Equilibrium flow curves of microparticulated whey protein (MWP) dispersions $20 \%(\mathrm{w} / \mathrm{w}) \mathrm{pH} 70.1 \mathrm{M} \mathrm{NaCl}$ as a function of temperature. The arrows indicate direction of change of shear rate. ( $T=5^{\circ} \mathrm{C}$ (E) $20^{\circ} \mathrm{C}$ ( $\Delta$ ) $40^{\circ} \mathrm{C}$

The apparent viscosity values remained constant at $0.02 \mathrm{~Pa} . \mathrm{s}$ for a shear rate of 100 and $50 \mathrm{~s}^{-1}$. Viscosity values at lower shear rates increased rapidly by a factor of 2,5 and 8 at 5,1 and 0.5 $\mathrm{s}^{-1}$, respectively, before reaching a pseudoplateau value. Thus, the apparent viscosity was both shear and time dependent, and increased when shear rate decreased (antithixotropic behaviour) or when MWP dispersion aged with time (results not shown).

Another illustration of the shear dependency of viscosity is given on Fig. 3 where the shear stress was plotted as a function of shear rate (equilibrium flow curves) for three different temperatures. Results clearly showed that the flow behaviour of MWP dispersion was non-newtonian like whatever the temperature used, the shear stress decreasing as the shear rate increased (shear-thinning like behaviour). The second characteristic of the flow curves was that an inverse hysteresis loop was present. The reverse flow curve obtained by decreasing shear rates was higher in stress values than the direct one corresponding to the ascending shear rates. The inverse hysteresis loop was increased with decreasing temperature.

The results indicated that the apparent viscosity of MWP dispersion decreased as the shear rate increased, but also that a time dependent process in the dispersion was established under shear giving rise to the hysteresis loop. The application of high shear rates would induce the arrangement of 
MWP in the direction of shear and/or the destruction of some «structure $\gg$ in the system (breakdown of protein aggregates). A complex structuration/destructuration (low shear rate/high shear rate) equilibrium of the medium would establish depending on the shear rate applied, this process being reinforced at low temperature.

The presence of some structure in initial MWP dispersion was investigated by a stress relaxation test (shear rate $1.66 \mathrm{~s}^{-1}$, Fig. 4). The stress overshoot observed (see insert on the figure) gave evidence of shear-induced disruption of structures initially present in the dispersion. Thereafter, a permanent regime was established where shear stress linearly increased with time indicating that the system flowed. After cessation of shear (relaxation), the shear stress returned to zero in a few seconds ( $30 \mathrm{~s}$ ) and revealed the liquid-like character of the system.

Another illustration of the presence of some structure in the MWP dispersion was given on Fig. 5 where the mechanical spectrum of the dispersion was shown. The system displayed a viscoelastic character with $\mathrm{G}^{\prime}$ values always higher than $G^{\prime \prime}$ values even at low frequencies. However, $\mathrm{G}^{\prime}$ decreased gradually with decreasing frequency and suggested that MWP dispersion had a liquidlike viscoelastic behaviour. This observation led to the same conclusions as those reported from relaxation measurements, MWP dispersion was a «structured» liquid. The structures would be

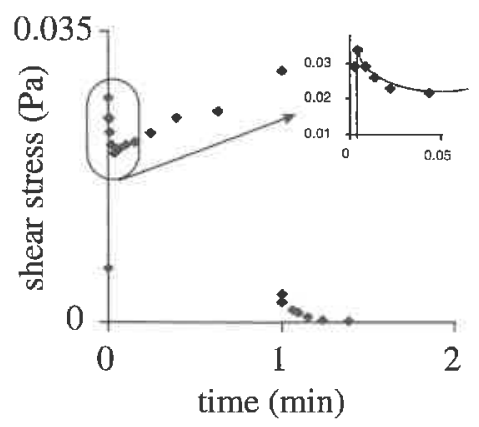

Fig. 4. Stress relaxation test at $T=20^{\circ} \mathrm{C}$ of microparticulated whey protein (MWP) dispersion $20 \%$ (w/w) pH $70.1 \mathrm{M} \mathrm{NaCl}$ as a function of time. Shear rate applied, $1.66 \mathrm{~s}^{-1}$, insert magnifies the shear stress peak (《stress overshoot») observed at the shortest times.

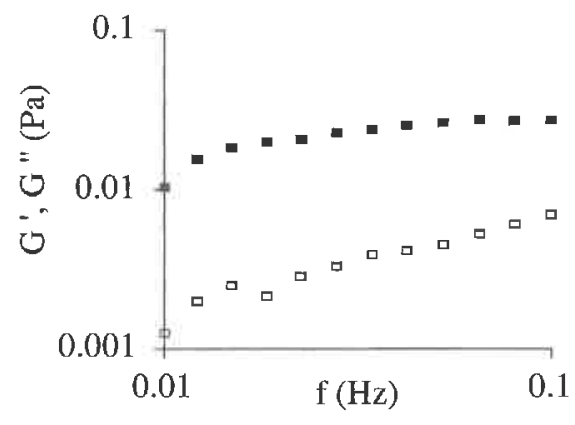

Fig. 5. Frequency sweep at $T=20^{\circ} \mathrm{C}$ of microparticulated whey protein (MWP) dispersion $20 \%(\mathrm{w} / \mathrm{w}) \mathrm{pH} 70.1 \mathrm{M} \mathrm{NaCl}$. Strain amplitude: 0.1. (口) $\mathrm{G}^{\prime} ;(\square) \mathrm{G}^{\prime \prime}$.

highly sensitive to shear due to the low energy implied in the MWP interactions.

\subsection{Rheological properties of mixed gels}

The gelation kinetics (Fig. 6) of BLG in the presence of various MWP concentrations were studied through the evolution of $\mathrm{G}^{\prime}(\mathrm{Pa})$. The effective BLG concentrations were of $4.01,4.06$, $4.11,4.22$ and $4.89 \%$ (w/w) for $0.1,1,2,4$ and $16 \%(\mathrm{w} / \mathrm{w})$ MWP added to the BLG network.

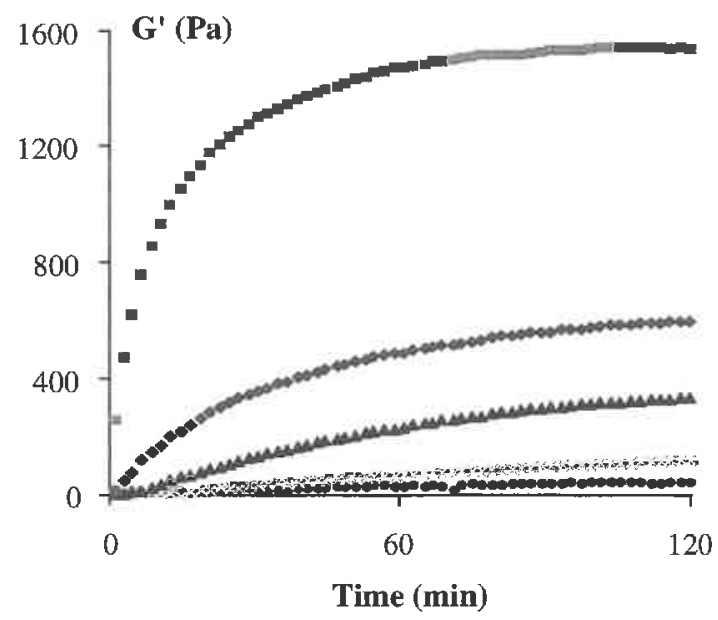

Fig. 6. Evolution of the storage modulus $\mathrm{G}^{\prime}(\mathrm{Pa})\left(T=80^{\circ} \mathrm{C}\right.$, $f=1 \mathrm{~Hz}, \gamma_{0}=0.01$ ) as a function of time for $\beta$-lactoglobulin (BLG) gel $(4 \% \mathrm{w} / \mathrm{w})$ and BLG:microparticulated whey proteins (MWP) mixed gels for different MWP concentrations at $\mathrm{pH} 7$ in $0.1 \mathrm{M} \mathrm{NaCl}$. (-) BLG alone; (-) BLG $4 \%$

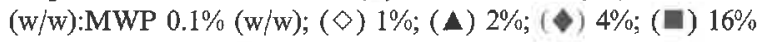
(total BLG concentration, see text). 


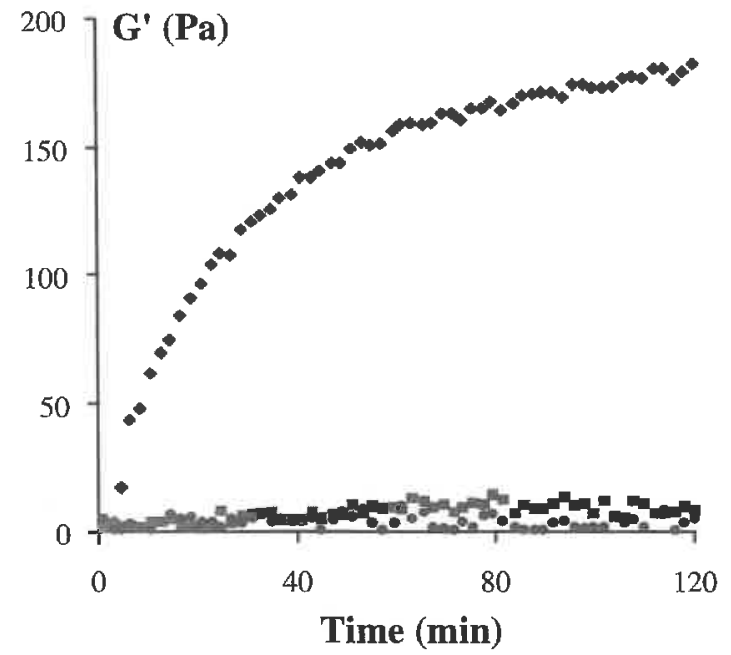

Fig. 7. Evolution of the storage modulus $\mathrm{G}^{\prime}(\mathrm{Pa})\left(T=80^{\circ} \mathrm{C}\right.$, $\left.f=1 \mathrm{~Hz}, \gamma_{0}=0.01\right)$ as a function of time for $\beta$-lactoglobulin (BLG) gel $(2 \% \mathrm{w} / \mathrm{w})$, microparticulated whey protein (MWP) dispersion (16\% w/w) and BLG:MWP mixed gel at $\mathrm{pH} 7$ in 0.1 $\mathrm{M} \mathrm{NaCl}$. (•) BLG alone; (回) MWP alone; (†) BLG 2\% (w/w):MWP 16\% (w/w) [total BLG concentration: $2.89 \%(w /$ w)].

The kinetics obtained for formation of mixed gels displayed a lag phase, an exponential growth phase and a stationary phase with a more or less marked plateau region after $2 \mathrm{~h}$. In the particular case of MWP:BLG ratios of 1:1.06 and 3.3:1, an absence of lag phase and a rapid increase of exponential growth phase were observed. Moreover, the plateau region was reached sooner than for lower MWP concentrations. The $\tan \delta$ values were constant around 0.08 whatever MWP concentration used and revealed the high elastic feature of mixed gels. The first observation based on the kinetic results was that the gelled systems did not seem to consist of a continuous BLG network with a $\ll$ free $\gg$ flowing liquid in between.

Fig. 7 described $G^{\prime}$ values measured versus heating time for BLG matrix alone $(2 \% \mathrm{w} / \mathrm{w})$, MWP dispersion alone $(16 \% \mathrm{w} / \mathrm{w})$ and mixed gel (MWP:BLG ratio 5.5:1). A 'synergestic' or 'cooperative' effect of MWP on the formation of BLG network was observed. While both MWP and BLG solutions alone gave very low moduli values, mixed systems displayed storage moduli in accordance with the formation of a network. It was, therefore, believed that some active constituents in the MWP dispersion participated to the enhancement of the mechanical properties of BLG network. The constituents allowing modulate mechanical properties may be the MWP themselves, the ions present in the powder, the lactose or the extra native BLG fraction. In fact, the slight increase of BLG concentration due to the addition of MWP $(+0.89 \%$ at the highest concentration) was not sufficient to explain a so large increase of the storage modulus.

Fig. 8 reported the evolution of $\mathrm{G}^{\prime}(\mathrm{Pa})$ as a function of MWP massic fraction. $\mathrm{G}^{\prime}$ values were recorded after quenching gels at $25^{\circ} \mathrm{C}$. The stability of gels appeared to be inversely proportional to gelation rate. Aggregates slowly grew in the case of BLG solution, resulting in a stable gel after quenching. On the contrary, less stable gels were obtained with mixed systems that quickly aggregated. This trend seems to be quite general in the aggregation and gelation processes implying globular protein material, in the sense that fast aggregation rate induces the formation of coarse structures and time unstable gels [6]. Looking at the storage moduli values obtained on MWP:BLG mixed gels, it appeared that MWP addition, in the limit of a MWP:BLG 1:1.06 ratio, reinforced $\mathrm{BLG}$ network. A «synergy $\gg$ be-

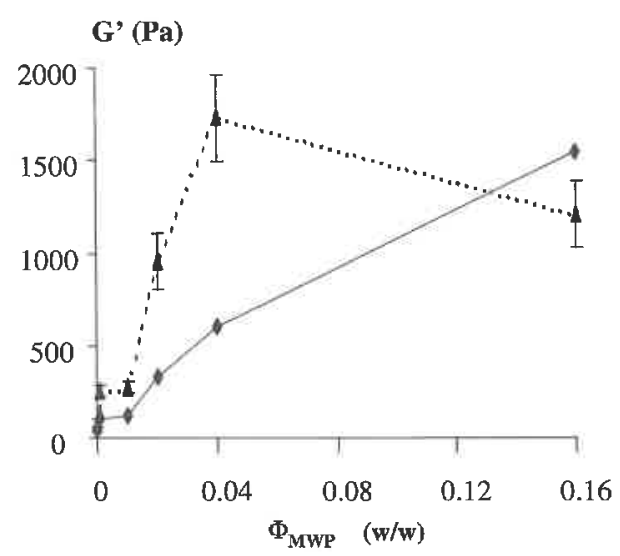

Fig. 8. Evolution of the storage modulus $\mathrm{G}^{\prime}(\mathrm{Pa})$ at $80^{\circ} \mathrm{C}(1$ $\left.\mathrm{Hz}-\gamma_{0}=0.01\right)$ and after quenching at $25^{\circ} \mathrm{C}\left(1 \mathrm{~Hz}-\gamma_{0}=0.03\right)$ of microparticulated whey proteins (MWP): $\beta$-lactoglobulin (BLG, 4\% w/w) mixed gels as a function of MWP massic fraction. (- -$) T=80^{\circ} \mathrm{C}$; (-- $\left.\Delta-\right) T=25^{\circ} \mathrm{C}$. 


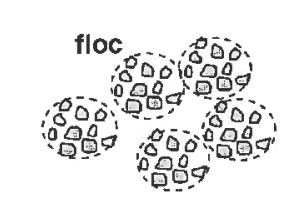

Progressive Hydration and Flocculation

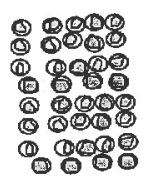

Disruption of flocs

under high shear rate

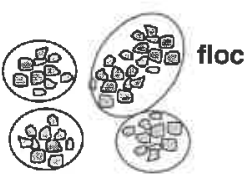

Formation of new flocs

\section{Ageing Time}

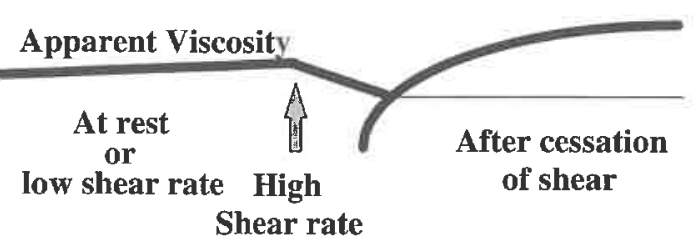

Fig. 9. Possible physical interpretation of microparticulated whey protein (MWP) dispersion behaviour under shear.

tween MWP and BLG aggregates was identified. For higher MWP:BLG ratio, MWP addition increased the aggregation kinetic but reduced gel stability as a loss of elasticity appeared after quenching. The increase of $\tan \delta$ values from 0.08 to 0.17 with the increase of MWP concentration appeared for a MWP:BLG ratio 3.3:1. Higher ratios induced a decrease of $\tan \delta$ values around 0.12 .

\section{Discussion}

The antithixotropy behaviour of MWP dispersion was first demonstrated by Giordano et al. [7] on lysozyme solutions. This behaviour was explained in terms of the building up of a structure that was both time and shear dependent. Similar observations were reported by Matsumoto and Chiba [8] on native ovalbumin solutions and by Renard et al. [9] on native $\beta$-lactoglobulin solutions. A physical interpretation of MWP behaviour under shear is suggested on Fig. 9. The structures built at rest or low shear rate (antithixotropy, stress overshoot, liquid-like viscoelastic character) were thought to be due to progressive flocculation under shear (orthokinetic aggregation). This phenomenon induced an increase of the apparent viscosity of the dispersion, this increase being time, shear and temperature dependent. Both thixotropic and antithixotropic behaviour were observed on highly concentrated whey protein concentrate solutions depending on temperature used [10]. At high shear rate, the decrease of viscosity values could be related to the disruption of flocs. The phenomenon was reversible as new flocs were formed just after cessation of shear. Is the orthokinetic aggregation of globular proteins and MWP an important feature in the subsequent formation of aggregates under heating remains an opened question. Nevertheless, the ability of these materials to flocculate under low shear rate may be of crucial importance in the aggregation processes revealed by means of small amplitude dynamical rheology. The making/breaking equilibrium of structures building up with time was demonstrated in the case of whey proteins at both low and high shear rates but also at both low and high protein concentrations [10-12].

The mechanical properties of BLG network were largely reinforced with increasing MWP concentration. This result suggested that a 'synergy' or 'cooperativity' between the two components occured depending on the composition of MWP dispersion.

\subsection{Native $\beta$-lactoglobulin fraction}

A possible effect of NSP fraction on the network formation was previously eliminated.

\subsection{Lactose fraction}

Some publications reported that the effect of various sugars including lactose was to inhibit the thermal gelation process of whey proteins $[13,14]$. The inhibition would cause a decrease in the $G^{\prime}$ values of formed networks. The mechanism implied would be pairwise hydrophobic interactions involving both solvent and protein. An alternative mechanism by which lactose inhibits whey protein gelation could be the formation of Schiff base products between lactose and amine groups of whey protein [14]. Whatever the mechanism involved, the general consequence of adding sugars is to decrease the mechanical properties of protein gels. 


\subsection{Ions fraction}

The enhancement of elasticity for mixed network could be explained by the presence of ions in MWP powder. It has been shown $[15,16]$ that an increase in the ionic strength results in a screening effect. The electrostatic interactions between proteins are reduced, promoting the aggregation process. The ionic strength for the highest MWP concentration, based on the ions fraction present in the powder, was of $0.16 \mathrm{M}$. On the other hand, a $4 \%$ BLG concentration corresponded to an ionic strength of $0.04 \mathrm{M}$. A comparison of $\mathrm{G}^{\prime}$ values obtained after quenching for a $4 \% \mathrm{BLG}$ network formed in $0.2 \mathrm{M} \mathrm{NaCl}$ and for a MWP:BLG mixed gel at the highest ratio (total ionic strength of $0.2 \mathrm{M}$ ) gave 125 and 3610 $\mathrm{Pa}$, respectively. This result demonstrated that ions initially present in MWP sample were not a critical parameter to explain the large increase of elasticity in mixed networks.

\subsection{Microparticulated whey protein flocculation process}

Flocs of large size were obtained from MWP during gel formation. Heating MWP dispersion gave storage moduli in agreement with a flocculation process. Recent results obtained by diffusing wave spectroscopy on MWP dispersions revealed the existence of large flocs formed under temperature (data not shown). The existence of both aggregation and flocculation under heating could explain the high level of connectivity in mixed systems. Similar conclusions were given by van Vliet [17] to explain large value of storage modulus in the case of acid milk gels mixed with milk proteins-stabilized fat globules.

\section{5. $\beta$-lactoglobulin-microparticulated whey protein (soluble fraction) co-aggregation}

The SAP fraction present in MWP dispersion could give rise to some 'cooperative' effects in the gelation process. Previous study demonstrated that the presence of soluble aggregates in a gelling material increased both gelation kinetics and mechanical properties of resulting gels [18]. The solu- ble aggregates could be directly implied in BLG aggregation and would produce a co-polymer, BLG aggregate-MWP soluble aggregate-BLG aggregate or BLG monomer-MWP soluble aggregate-BLG monomer.

\subsection{Disruptive effects}

Some heterogeneities developed in mixed gels with increasing MWP concentration. The consequence was an increase of the viscous part in the network. Flocculation of MWP would disturb the protein strands formation by steric hindrance or excluded volume effects and would lead to large inhomogeneities in the protein network. An alternative explanation would be that mixed system could be considered as a segregative system where thermodynamic incompatibility between MWP and BLG aggregates applied above a critical total concentration of both components. A microphase separation during gelation process could thus be promoted. Inhomogeneities at large scale could develop and decrease the viscoelastic properties of mixed gels.

A hypothetical model of mixed MWP:BLG gels is given on Fig. 10. The model was partly based on conclusions previously drawn from large deformation studies [19]. The a priori opposite effects MWP on rheological properties of mixed gels were also depicted.

Both an interaction of MWP SAP fraction with BLG aggregates and MWP flocculation would occur at low MWP concentration. While strands of BLG would interact with some MWP aggregates to give a 'co-polymer', flocculation of some MWP would occur inside the pores of the matrix. An increase of elasticity in the network would be the overall consequence. Further microscopic studies will be necessary to check this hypothetical model. With increasing MWP concentration, flocs of large size that would provoke steric hindrance and matrix breakdown were formed. The consequence would be the deleterious effects encountered in the mechanical properties of mixed gels. The system lost part of its elasticity, probably due to the apparition of heterogeneities. Heterogeneities are areas in the network where aggregates would be closely packed to each other giving rise 

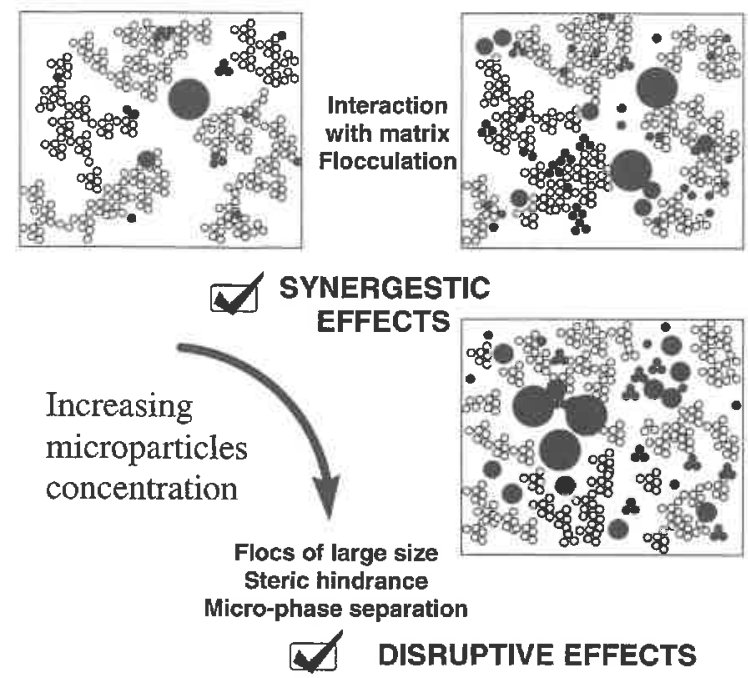

Fig. 10. Hypothetical model of the mechanism of interaction between microparticulated whey proteins (MWP) and $\beta$-lactoglobulin (BLG) network. (At low MWP concentration, two identifiable units in the matrix, MWP and BLG; at high MWP concentration, large MWP flocs disrupted the strands of the matrix).

to local aggregate overconcentrations and microphase separated regions.

\section{Conclusion}

Preliminary results obtained on MWP in suspension or included in a globular protein network revealed that the degree of flocculation was important in the final structure of the material. The MWP dispersions developed an antithixotropic character when low shear rate was applied to the system even at low temperature. Similar results were observed on globular protein solutions and could be interpreted in terms of an orthokinetic aggregation.

MWP participated to the formation and reinforcement of heat-induced BLG gels. Some interactions between MWP soluble fraction and BLG aggregates would occur leading to a large increase in the mechanical properties of mixed gels. However, increasing MWP concentration induced heterogeneities in the network and micro-phase separation due to steric effects or thermodynamic incompatibility between the two components. Recent brownian dynamics simulations on mixed particle gels gave evidence that small filler particles increased the gelation kinetics more strongly than large ones [20]. Moreover, it was shown that the incorporation of filler particles in a network formed by small colloidal particles increased the storage and loss moduli. In that sense, the near future will be devoted to look at the influence of the MWP size on the mechanical properties of globular protein network.

\section{References}

[1] C. Sanchez, P. Paquin, in: S. Damodaran, A. Paraf (Eds.), Food Proteins and their Applications, Marcel Dekker, New York, 1997, Chapter 17.

[2] M.J. Alonso, in: S. Cohen, H. Bernstein (Eds.), Drugs and the Pharmaceutical Sciences, CRC Press, Boca Raton, 1996, Chapter 7.

[3] C. Sanchez, M. Pouliot, S.F. Gauthier, P. Paquin, J. Agric. Food Chem. 45 (1997) 2384.

[4] J.N. de Wit, Th, van Kessel, Food Hydrocoll 2 (1996) 143.

[5] R.J. Pearce, Aust. J. Dairy Technol. 38 (1983) 114.

[6] J. Lefebvre, D. Renard, A.C. Sanchez Gimeno, Rheol. Acta, (1998) (in press).

[7] R. Giordano, A. Grasso, J. Teixeira, F. Wanderlingh, U. Wanderlingh, Croatica Chem. Acta 65 (1992) 411.

[8] T. Matsumoto, J. Chiba, J. Chem. Soc. Faraday Trans. 86 (1990) 2877.

[9] D. Renard, M.A.V. Axelos, F. Boué, J. Lefebvre, J. Chim. Phys. 93 (1996) 998.

[10] M.R. Alizadehfard, D.E. Wiley, J. Dairy Res. 63 (1996) 315.

[11] P. Pradipasena, C.-K. Rha, J. Texture Stud. 8 (1977) 311.

[12] Q. Tang, P.A. Munro, O.J. McCarthy, J. Dairy Res. 60 (1993) 349.

[13] J.M. Garrett, R.A. Stairs, R.G. Annett, J. Dairy Sci. 71 (1988) 10.

[14] Q. Tang, O.J. McCarthy, P.A. Munro, J. Agric. Food Chem. 42 (1994) 2126.

[15] D. Renard, J. Lefebvre, Int. J. Biol. Macromol. 14 (1992) 287.

[16] D. Renard, J. Lefebvre, M.C.A. Griffin, W.G. Griffin, Int. J. Biol. Macromol. 22 (1998) 41.

[17] T. van Vliet, Coll. Polym. Sci. 266 (1988) 518.

[18] D.J. McClements, M.K. Keogh, J. Sci. Food Agric. 69 (1995) 7.

[19] C. Sanchez, D. Renard, M. Pouliot, P. Paquin, J. Hardy, J. Agric. Food Chem. 1998 (submitted for publication).

[20] C.M. Wijmans, E. Dickinson, J. Chem. Soc. Faraday Trans. 94 (1998) 129. 
